\title{
The MARCKS protein amount is differently regulated by calpain during toxic effects of methylmercury between SH-SY5Y and EA.hy926 cells
}

\author{
Cuong Van DAO ${ }^{1,2)}$, Mitsuya SHIRAISHI ${ }^{1) *}$ and Atsushi MIYAMOTO ${ }^{1)}$ \\ ${ }^{1)}$ Department of Veterinary Pharmacology, Joint Faculty of Veterinary Medicine, Kagoshima University, 1-21-24 \\ Korimoto, Kagoshima 890-0065, Japan \\ 2)Department of Veterinary Pharmacology, Faculty of Animal Husbandry and Veterinary Medicine, \\ Thai Nguyen University of Agriculture and Forestry, Group 10, Quyet Thang Commune, Thai Nguyen City, \\ Thai Nguyen, Vietnam
}

\section{J. Vet. Med. Sci. \\ 79(12): 1931-1938, 2017}

doi: 10.1292/jvms.17-0473

Received: 24 August 2017

Accepted: 5 October 2017

Published online in J-STAGE:

18 October 2017

\begin{abstract}
Methylmercury $(\mathrm{MeHg})$ is an environmental pollutant that shows severe toxicity to humans and animals. However, the molecular mechanisms mediating MeHg toxicity are not completely understood. We have previously reported that the MARCKS protein is involved in the $\mathrm{MeHg}$ toxicity to SH-SY5Y neuroblastoma and EA.hy926 vascular endothelial cell lines. In addition, calpain, a $\mathrm{Ca}^{2+}$-dependent protease, is suggested to be associated with the MeHg toxicity. Because MARCKS is known as a substrate of calpain, we studied the relation between calpain activation and cleavage of MARCKS and its role in MeHg toxicity. In SH-SY5Y cells, MeHg decreased cell viability along with increased calcium mobilization, calpain activation and a decrease in MARCKS amounts. However, pretreatment with calpain inhibitors attenuated the decrease in cell viability and MARCKS amount induced only by $1 \mu \mathrm{M}$ but not by $3 \mu \mathrm{M} \mathrm{MeHg}$. In cells with a MARCKS knockdown, calpain inhibitors failed to attenuate the decrease in cell viability caused by MeHg. In EA.hy926 cells, although MeHg caused calcium mobilization and a decrease in MARCKS levels, calpain activation was not observed. These results indicate that the participation of calpain in the regulation of MARCKS amounts is dependent on the cell type and concentration of MeHg. In SH-SY5Y cells, calpain-mediated proteolysis of MARCKS is involved in cytotoxicity induced by a low concentration of MeHg.
\end{abstract}

KEY WORDS: calpain, MARCKS, methylmercury

Methylmercury $(\mathrm{MeHg})$ is a potent environmental toxic pollutant that is generated by bacterial methylation of inorganic mercury in an aquatic environment [37]. The central nervous system is the main target of MeHg toxicity [10, 11, 40] in humans and experimental animal models [5]. For example, prenatal $\mathrm{MeHg}$ intoxication has been implicated in neurodevelopmental disorders such as mental retardation and motor and cognitive dysfunction [17]. The cardiovascular system has also been reported as a target of $\mathrm{MeHg}[6,30]$. We recently showed that mice exposed to $\mathrm{MeHg}$ in vivo develop high blood pressure and impaired endotheliumdependent vasodilation [15].

Myristoylated alanine-rich C kinase substrate (MARCKS) is a major substrate of protein kinase $\mathrm{C}$ and is expressed in many tissues [1], including the brain and endothelial cells [18, 22, 35]. In neurons, the functions of MARCKS in dendrite branching, dendritic-spine morphology, growth cone guidance, neurite outgrowth and higher brain functions, such as learning and memory, have been reported $[4,13,20,23,33]$. In endothelial cells, MARCKS has been shown to regulate proliferation, cell migration, cell permeability and nitric oxide production [16, 18, 25, 39, 42]. We have previously reported that in human neuroblastoma and endothelial cell lines, MeHg induces a significant decrease in MARCKS amount, and that the decrease in cell viability induced by $\mathrm{MeHg}$ is accelerated in MARCKS knockdown cells [34, 39], suggesting that MARCKS plays an important role in MeHg cytotoxicity. However, the precise mechanisms underlying the regulation of MARCKS content by MeHg exposure remain unclear.

Calpain is a cytosolic, $\mathrm{Ca}^{2+}$-activated, neutral cysteine protease. The well-studied calpain isoforms, calpain 1 ( $\mu$-calpain) and calpain 2 (m-calpain), are ubiquitously expressed and regulate important functions of neuronal [2] and endothelial cells [12]. MeHg induces calpain activation, which is involved in MeHg cytotoxicity in vitro [7, 21, 31, 38] and in vivo [3, 41, 44]. Furthermore, regulation of MARCKS function by calpain proteolytic cleavage has been suggested [9, 19, 36].

*Correspondence to: Shiraishi, M.: shira-m@vet.kagoshima-u.ac.jp

(C2017 The Japanese Society of Veterinary Science

This is an open-access article distributed under the terms of the Creative Commons Attribution Non-Commercial No Derivatives (by-nc-nd) License. (CC-BY-NC-ND 4.0: https://creativecommons.org/licenses/by-nc-nd/4.0/) 
In the present study, we determined the contribution of MeHg-induced calpain activation to the regulation of full-length MARCKS content in a human neuroblastoma cell line, SH-SY5Y, and in a human endothelial cell line, EA.hy926, by means of different concentrations of $\mathrm{MeHg}$, potent cell-permeating calpain I and II inhibitors, or MARCKS small interfering RNA (siRNA) knockdown cells. Our results indicated that the participation of calpain in the regulation of MARCKS protein content was dependent on the cell type and concentration of MeHg. In SH-SY5Y cells, MARCKS proteolysis by calpain was found to be involved in cytotoxicity induced by a low concentration of MeHg. These findings add to our understanding of the distinct molecular mechanisms of MeHg-induced cytotoxicity toward different types of cells.

\section{MATERIALS AND METHODS}

\section{Cell culture}

SH-SY5Y and EA.hy926 cells (ATCC, Manassas, VA, U.S.A.) were grown in Dulbecco's modified Eagle's medium mixed at 1:1 with Ham's F-12 (Wako, Osaka, Japan) and in Dulbecco's modified Eagle's medium (Sigma-Aldrich, St. Louis, MO, U.S.A.) supplemented with $10 \%$ of fetal bovine serum, respectively. Both cell lines were grown at $37^{\circ} \mathrm{C}$ in a humidified atmosphere containing $5 \%$ of $\mathrm{CO}_{2}$. Two days before the experiments, the cells were seeded in 96-well plates or 35-mm dishes at a density of $7 \times 10^{4}$ (for SH-SY5Y cells) or $10^{4}$ cells $/ \mathrm{cm}^{2}$ (for EA.hy926 cells). In all the experiments, the cells were treated with MeHg chloride (Kanto Chemical, Tokyo, Japan) dissolved in distilled water for $24 \mathrm{hr}$ after $4 \mathrm{hr}$ of serum starvation.

\section{A cell viability assay}

To evaluate MeHg cytotoxicity, cell viability was measured using the WST- 8 assay Cell Counting Kit-8 (Dojindo, Kumamoto, Japan). SH-SY5Y or EA.hy926 cells in a 96-well plate were incubated with a $0.3 \mu \mathrm{M}$ calpain inhibitor, MDL-28170 (Santa Cruz Biotechnology, Santa Cruz, CA, U.S.A.) or calpeptin (Cayman Chemical, Michigan, MI, U.S.A.), dissolved in DMSO for 2 hr before addition of MeHg. DMSO (0.1\%) served as a vehicle control of calpain inhibitors. The absorbance of formazan dye solution in the WST-8 assay was measured on an Infinite M200 FA plate reader (TECAN, Männedorf, Switzerland).

\section{Measurement of intracellular $\mathrm{Ca}^{2+}$ mobilization}

This mobilization induced by MeHg was monitored by means of Calcium kit II -Fluo 4 (Dojindo) as previously described $[26,27]$. Cells in a 96-well plate were incubated with $2.5 \mu \mathrm{M}$ fluo-4 AM for $1 \mathrm{hr}$ at $37^{\circ} \mathrm{C}$. Fluo-4 fluorescence at $518 \mathrm{~nm}$ emission after excitation at $495 \mathrm{~nm}$ was measured using the Infinite M200 FA plate reader at $37^{\circ} \mathrm{C}$.

\section{Western blotting}

This procedure was performed as described elsewhere [34]. Cells in 35-mm dishes were treated with calpain inhibitors and $\mathrm{MeHg}$ as described above. The primary antibodies were an anti-MARCKS (JK-8) antibody (Santa Cruz Biotechnology), anti- $\alpha-$ fodrin ( $\alpha$ II-Spectrin; Enzo Life Sciences, New York, NY, U.S.A.), and anti- $\beta$-actin antibody (Sigma-Aldrich). Immunoreactive proteins were detected using the Luminata Forte Western HRP substrate (Millipore, Billerica, MA, U.S.A.) with a phosphorescence imager (myECL Imager; Thermo Scientific, Waltham, MA, U.S.A.), and quantified by densitometric analysis in the Image J software (NIH, Bethesda, MD, U.S.A.). Expression levels of MARCKS and $\alpha$-fodrin were normalized to the amount of $\beta$-actin.

\section{A knockdown of MARCKS}

ScreenFectA Plus (Wako) was employed for siRNA transfection procedures for both cell lines. MARCKS siRNA (HSS180966) and negative control siRNA were purchased from Invitrogen (Carlsbad, CA, U.S.A.). SH-SY5Y or EA.hy926 cells were mixed with 20 or $3.5 \mathrm{nM}$ siRNA, respectively, and then seeded in a 96-well plate or 35-mm dishes 2 days before experiments.

\section{Statistical analysis}

All values are expressed as mean \pm SEM. Statistical significance of differences between two means was evaluated by Student's $t$ test. Multiple comparisons were made by one-way analysis of variance followed by Dunnett's or Tukey's test. Differences were considered significant at $P<0.05$.

\section{RESULTS}

\section{Attenuation of the MeHg-induced decrease in cell viability by calpain inhibitors}

Treatment with MeHg for $24 \mathrm{hr}$ caused a decrease in viability of SH-SY5Y and EA.hy926 cells in a dose-dependent manner (Fig. 1A). The lower concentration of MeHg, $1 \mu \mathrm{M}$ for SH-SY5Y and $3 \mu \mathrm{M}$ for EA.hy 926 cells, elicited approximately a $30 \%$ decrease in cell viability, whereas the higher concentration of MeHg, $3 \mu \mathrm{M}$ for SH-SY5Y and $10 \mu \mathrm{M}$ for EA.hy926 cells, caused an approximately $60 \%$ decrease in cell viability (Fig. 1A). In SH-SY5Y cells, pretreatment with a $0.3 \mu \mathrm{M}$ calpain inhibitor, MDL28170 or calpeptin, for $2 \mathrm{hr}$ before addition of $\mathrm{MeHg}$ attenuated the decrease in cell viability induced by the low concentration $(1 \mu \mathrm{M})$ but not by the high concentration $(3 \mu \mathrm{M})$ of $\mathrm{MeHg}$ (Fig. 1B and 1C). In contrast, the decrease in cell viability induced by the low $(3 \mu \mathrm{M})$ or high $(10 \mu \mathrm{M})$ concentration of MeHg in EA.hy926 cells was not altered by the pretreatment with calpain inhibitors (Fig. 1D and 1E). 
(A)

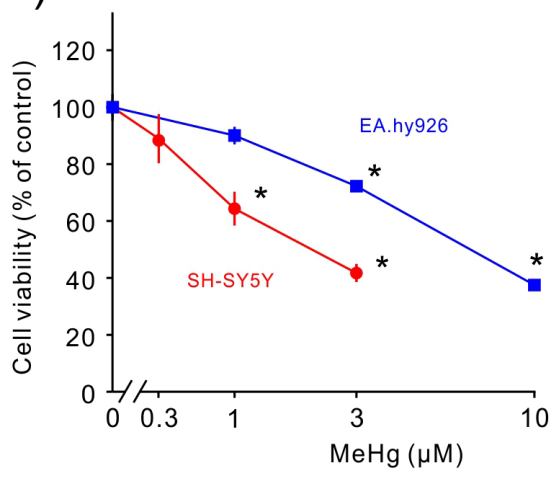

(B)

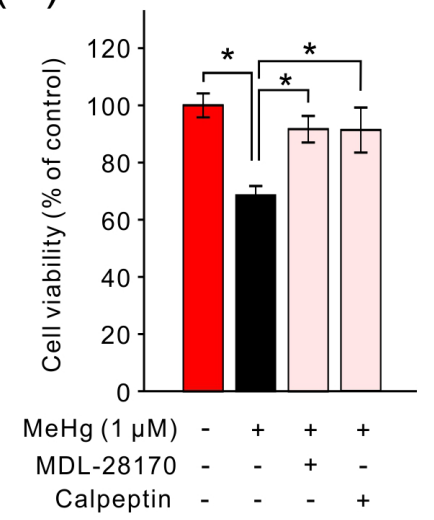

(C)

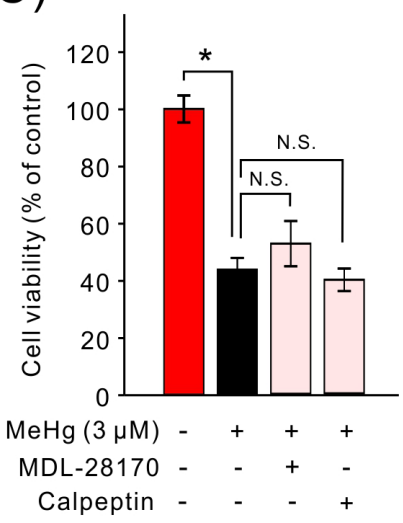

(D)

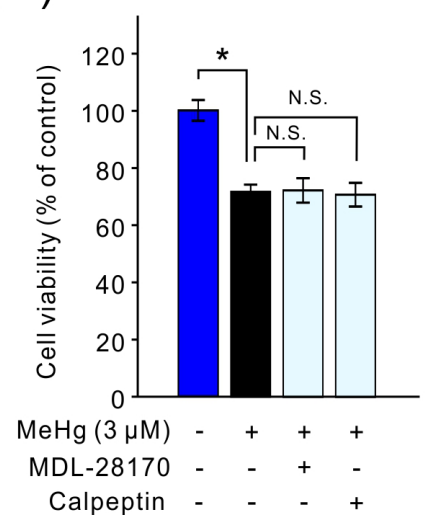

(E)

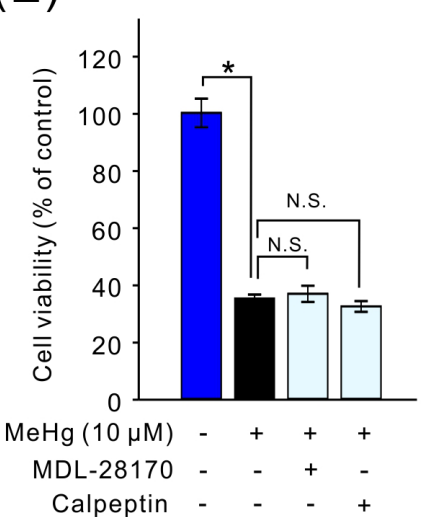

Fig. 1. Attenuation of the MeHg-induced decrease in cell viability by calpain inhibitors. MeHg induced a dose-dependent decrease in the viability of SH-SY5Y and EA.hy926 cells (A, $\mathrm{n}=9$ to 10$)$. Effects of calpain inhibitors (0.3 $\mu$ M MDL-28170 or calpeptin) on the decrease in cell viability induced by $1 \mu \mathrm{M}(\mathrm{B}, \mathrm{n}=9)$ or $3 \mu \mathrm{M}(\mathrm{C}, \mathrm{n}=9) \mathrm{MeHg}$ in SH-SY5Y cells. Effects of calpain inhibitors $(0.3 \mu \mathrm{M}$ MDL-28170 or calpeptin) on the decrease in cell viability induced by $3 \mu \mathrm{M}(\mathrm{D}, \mathrm{n}=5)$ or $10 \mu \mathrm{M}(\mathrm{E}, \mathrm{n}=5) \mathrm{MeHg}$ in EA.hy926 cells. Data are expressed as a percentage of vehicle-treated cells (control). Results are shown as mean $\pm \mathrm{SEM}$. $* P<0.05$ as compared with control (A) or as indicated (B-E). N.S.: not significant.

\section{Calcium mobilization and calpain activation induced by $\mathrm{MeHg}$}

Calpain inhibitors had different effects on the decrease in cell viability induced by $\mathrm{MeHg}$, which depended on the concentration of $\mathrm{MeHg}$ and cell type. Therefore, we confirmed the effect of $\mathrm{MeHg}$ on the intracellular $\mathrm{Ca}^{2+}$ concentration because calpain activation is mediated by intracellular $\mathrm{Ca}^{2+}$ mobilization. The low and high concentrations of $\mathrm{MeHg}$ significantly increased $\mathrm{Ca}^{2+}$ concentration in both types of cells (Fig. 2A and 2B).

Moreover, we quantified the MeHg-induced calpain activation in SH-SY5Y and EA.hy926 cells by monitoring the cleavage of $\alpha$-spectrin into $150 / 145 \mathrm{kDa}$ calpain-dependent spectrin breakdown products (SBDP) by western blotting. In SH-SY5Y cells, the low and high concentration of MeHg significantly increased the amounts of 150/145 kDa SBDP (Fig. 3A-C), suggesting that calpain was activated by MeHg in SH-SY5Y cells. The calpain activation by the low and high concentrations of MeHg was suppressed by pretreatment with calpain inhibitors although the inhibitors suppressed the decrease in cell viability induced only by the low concentration of $\mathrm{MeHg}$ (Fig. 1). On the other hand, in EA.hy926 cells, MeHg did not increase the amount of 150/145 kDa SBDP (Fig. 3D-F) in accordance with the results on the effect of calpain inhibitors on the MeHg-induced decrease in cell viability (Fig. 1).

\section{Attenuation of the MeHg-induced decrease in MARCKS amount by calpain inhibitors}

We have previously reported that a decrease in MARCKS amount plays an important role in the MeHg cytotoxicity in both SHSY5Y and EA.hy926 cells. Furthermore, it is known that MARCKS is cleaved by activated calpain in vitro [7, 21, 31, 38]. Therefore, we determined the effect of calpain inhibitors on the decrease in MARCKS amount induced by MeHg. In SH-SY5Y and EA.hy926 cells, treatment with the low or high concentration of MeHg significantly decreased full-length MARCKS amount as previously reported (Fig. 4). In SH-SY5Y cells, although calpain activation was elicited by both the low or high concentration of MeHg, calpain inhibitors suppressed only the decrease in MARCKS amount induced by the low concentration of MeHg; this result is in agreement with the effect of calpain inhibitors on the MeHg-induced decrease in cell viability (Fig. 4A-C). By contrast, in EA.hy926 cells, the MeHg-induced decrease in MARCKS amount was not affected by the pretreatment with calpain inhibitors (Fig. 4D-F). 
Effects of calpain inhibitors on the MeHg-induced decrease in cell viability and in MARCKS amount in SH-SY5Y cells with a MARCKS knockdown

To clarify the relation between the calpain-mediated decrease in MARCKS amount and the decrease in cell viability induced by $\mathrm{MeHg}$, we examined the effect of calpain inhibitors on the decrease in MARCKS amount and in viability induced by $\mathrm{MeHg}$ in MARCKS knockdown cells (Fig. 5). Amount of MARCKS in SH-SY5Y cells treated with MARCKS siRNA was decreased to approximately $40 \%$ of control cells. In MARCKS knockdown cells, the decrease in MARCKS amount by the low concentration of $\mathrm{MeHg}$ and the effect of calpain inhibitors on the MARCKS content were not observed (Fig. 5A and 5B). In accordance with this observation, the decrease in cell viability under the influence of the low concentration of $\mathrm{MeHg}$ was not altered by pretreatment with calpain inhibitors (Fig. 5C).

\section{DISCUSSION}

The aim of this study was to investigate the relation between calpain activation and proteolysis of MARCKS in MeHg toxicity to the SHSY5Y neuroblastoma cell line and EA.hy926 vascular endothelial cell line. In our previous studies, amount of the full-length MARCKS protein was significantly decreased by treatment with $\mathrm{MeHg}$, and this protein seems to play a key role in the $\mathrm{MeHg}$ toxicity $[34,39]$. In addition, the involvement of calpain in the $\mathrm{MeHg}$ toxicity had been suggested $[3,7,21,31,38,41,44]$. Hence, it is important to identify the precise mechanisms behind the regulation of MARCKS levels by $\mathrm{MeHg}$ exposure.

We first determined the involvement of calpain in the MeHg-induced decrease in viability of SH-SY5Y and EA.hy926 cells by means of potent cell-permeating calpain I and II inhibitors: MDL-28170 and calpeptin (Fig. 1). In SH-SY5Y cells, the decrease in cell viability induced by the low concentration of $\mathrm{MeHg}$, which causes approximately a $30 \%$ decrease, was significantly attenuated by the pretreatment with calpain inhibitors (Fig. 1B) as previously reported in rat cerebellar granules [31]. However, the pretreatment effects of calpain inhibitors were not observed at the high concentration of $\mathrm{MeHg}$ (Fig. 1C). We confirmed that the low and high concentrations of $\mathrm{MeHg}$ caused not only a significant increase in the fluo-4 fluorescence ratio in comparison with vehicle-treated cells (Fig. 2A) but also a significant increase in the amount of calpaingenerated $150 / 145 \mathrm{kDa}$ SBDP. Furthermore, the increase in $150 / 145 \mathrm{kDa}$ SBDP amounts was almost abrogated by the pretreatment with calpain inhibitors (Fig. 3B and 3C). These results suggested that the participation of calpain in $\mathrm{MeHg}$ toxicity was different at different concentrations of MeHg in SH-SY5Y cells, even though calpain was activated by both the low and high concentration of MeHg. In contrast, in EA.hy926 cells, although MeHg significantly decreased cell viability, the pretreatment effect of calpain inhibitors was not observed regardless of the concentration of $\mathrm{MeHg}$ (Fig. 1D and 1E). MeHg significantly increased the fluo-4 fluorescence ratio (Fig. 2B), while calpain activation by MeHg was not detected (Fig. 3E and 3F). Since expression of calpain in EA.hy926 cells has been reported [29], it seems that the zero effect of calpain inhibitors on the MeHg-induced decrease in viability of EA.hy926 cells was due to the absence of calpain activation by $\mathrm{MeHg}$. It has been reported that calpain activation was regulated not only by calcium mobilization but also by phospholipids or ERK/MAP kinase signaling pathway [32,43], suggesting that MeHg-induced signaling events in EA.hy926 cells may not be sufficient to induce calpain activation.

Next, we focused on the contribution of calpain to the MeHg-induced downregulation of MARCKS because we have previously reported the participation of MARCKS in MeHg toxicity to SH-SY5Y and EA.hy926 cells [34, 39]. It has been shown that calpain regulates MARCKS function by proteolytic cleavage [9] during myoblast fusion, adhesion, and migration [8, 9] and airway mucin secretion [19]. In accordance with the results on cell viability, the MeHg-induced decrease in full-length MARCKS amount was significantly suppressed by the pretreatment with calpain inhibitors at the low concentration of MeHg (Fig. 4B), but not at the high concentration of MeHg in SH-SY5Y cells (Fig. 4C). Besides, calpain inhibitors had no effect on the decrease in MARCKS amounts by MeHg in EA.hy926 cells (Fig. 4E and 4F). These results suggest that the low concentration of MeHg downregulates MARCKS through calpain activation in SH-SY5Y cells.

Finally, we examined the effect of calpain inhibitors on the MeHg-induced decrease in viability and downregulation of full- 
(A)

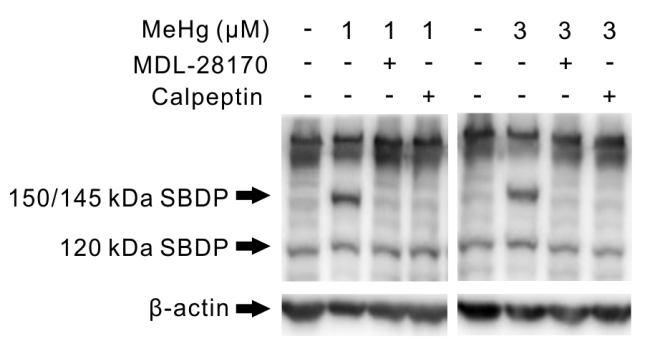

(D)

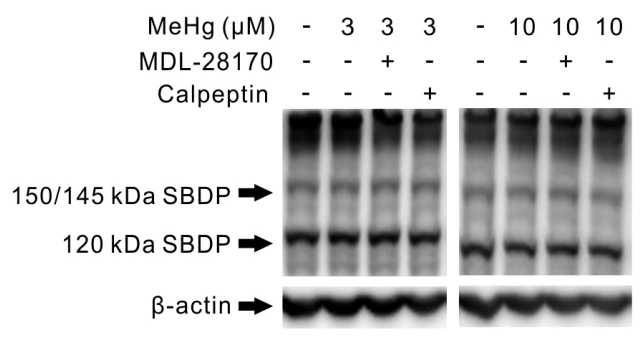

(B)

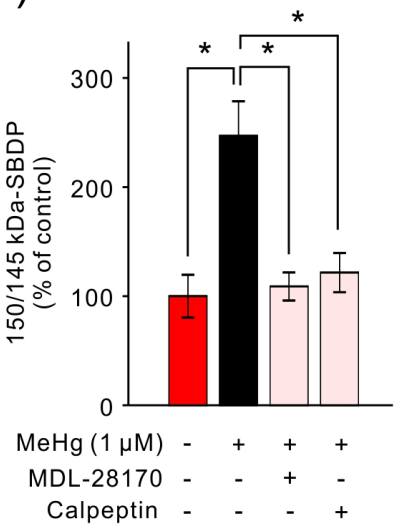

(E)

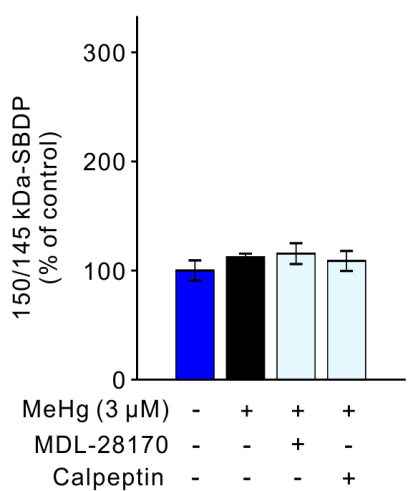

(C)

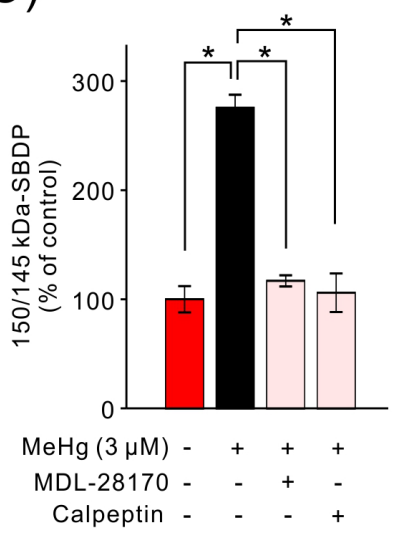

(F)

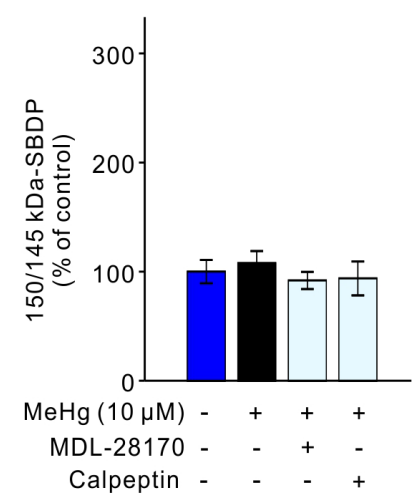

Fig. 3. Calpain activation induced by MeHg, and effects of calpain inhibitors. The MeHg-induced change in 150/145 kDa SBDP was investigated in SH-SY5Y cells $(A-C, n=5)$ and EA.hy926 cells $(D-F, n=6)$. Representative immunoblots of 150/145 and $120 \mathrm{kDa}$ SBDP and $\beta$-actin with specific antibodies are shown (A and D). Changes in 150/145 kDa SBDP were determined by densitometric analysis (B, C, E and F). Data are expressed as a percentage of vehicle-treated cells (control). Results are shown as mean $\pm \mathrm{SEM} ; * P<0.05$.

length MARCKS in SH-SY5Y cells with the MARCKS knockdown (Fig. 5). In the MARCKS knockdown cells, the decrease in MARCKS amount by the low concentration of MeHg was not detected (Fig. 5B). In addition, pretreatment with calpain inhibitors had no effect on the amount of full-length MARCKS. On the other hand, a significant decrease in cell viability caused by the low concentration of $\mathrm{MeHg}$ in control cells was augmented in cells with the MARCKS knockdown (Fig. 5C) as previously reported [34], suggesting that MARCKS plays a key role in MeHg cytotoxicity. In line with the result on MARCKS content, pretreatment with calpain inhibitors did not alter the decrease in cell viability induced by MeHg. These results suggest that the calpain-mediated decrease in MARCKS amount mediates MeHg toxicity to SH-SY5Y cells at the low concentration of this chemical. Recently, Pierozan et al. proposed that the cytoskeleton is an end point of $\mathrm{MeHg}$ cytotoxicity [28]. Because it has been demonstrated that in vitro cleavage of MARCKS by calpain increases its actin-binding activity [41], MARCKS cleaved by calpain may exert its effect via actin reorganization, in addition to the increase in MARCKS phosphorylation [34] in MeHg toxicity to SH-SY5Y cells.

Here, we demonstrated that the function of calpain in the regulation of MARCKS protein amounts is dependent on the cell type and concentration of MeHg. In SH-SY5Y cells, proteolysis of MARCKS by calpain mediates the cytotoxicity caused by the low concentration of $\mathrm{MeHg}$. The mechanisms of the MeHg-driven decrease in cell viability and in MARCKS amount remain unknown in EA.hy926 cells and for the high concentration MeHg in SH-SY5Y cells. Interestingly, cleavage of MARCKS by calpain is dependent of its phosphorylation and localization [9]. In addition, it has been reported that cathepsin B, a lysosomal cysteine protease, and ubiquitin-proteasome proteolytic pathway were involved in degradation of MARCKS in neurons [14, 24]. However, it has not been reported whether the cathepsin B or ubiquitin-proteasome system participates in mechanisms of $\mathrm{MeHg}$ toxicity on SH-SY5Y and EA.hy926 cells. Involvement of these mechanisms should be clarified for a better understanding of the role of MARCKS proteins in MeHg cytotoxicity. A schematic representation of the regulation of full-length MARCKS amounts by MeHg in SH-SY5Y and EA.hy926 cells is provided in Fig. 6. These findings should elucidate the distinct molecular mechanisms of MeHg toxicity to various cell types. 
(A)

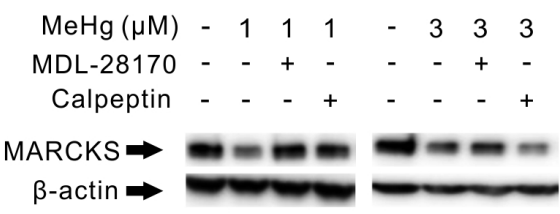

(D)

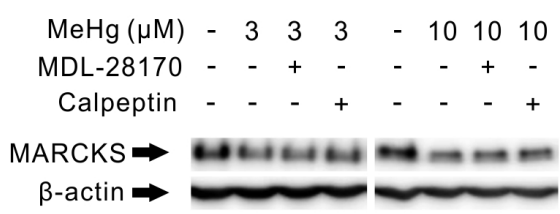

(B)

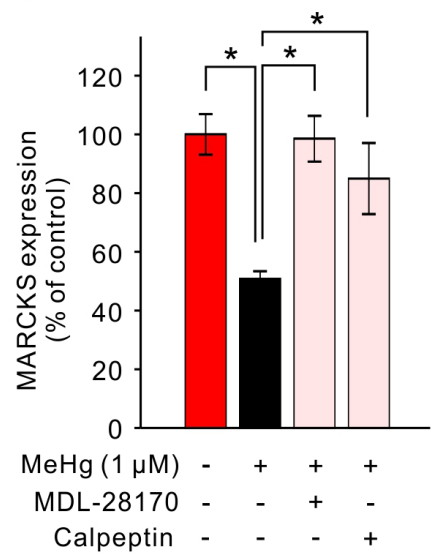

(E)

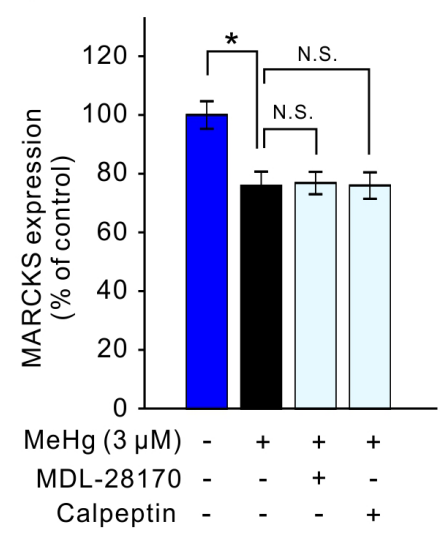

(C)

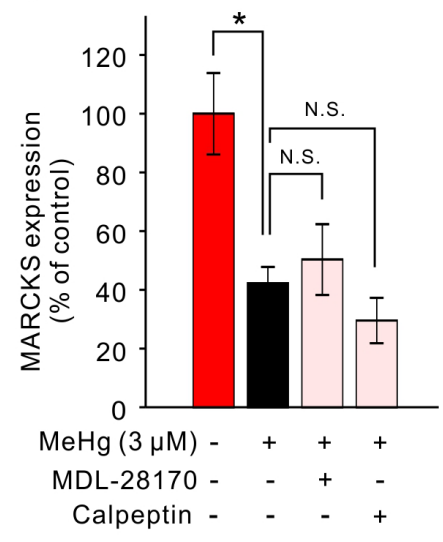

(F)

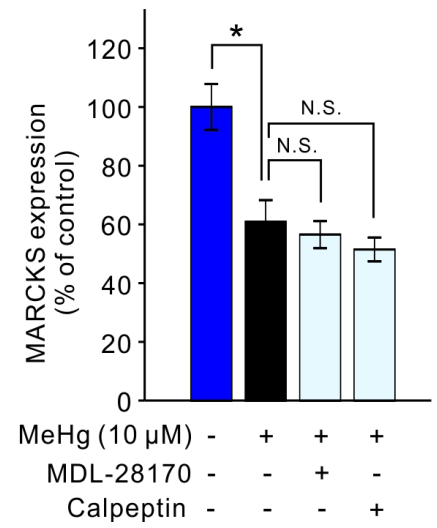

Fig. 4. Attenuation of the MeHg-induced decrease in MARCKS amount by calpain inhibitors. The MeHg-induced decrease in full-length MARCKS amounts and effects of calpain inhibitors were studied in SH-SY5Y cells (A-C, n=5) and EA.hy926 cells (D-F, $n=6$ ). Representative immunoblots of MARCKS and $\beta$-actin with specific antibodies are shown (A and D). Changes in MARCKS content were quantified by densitometric analysis (B, C, E and F). Data are expressed as a percentage of vehicletreated cells (control). Results are shown as mean \pm SEM; $* P<0.05$. N.S.: not significant.

ACKNOWLEDGMENT. This work was supported by a Grant-in-Aid for Scientific Research (C) (No. 26450407) from the Japan Society for the Promotion of Science (JSPS).

\section{REFERENCES}

1. Albert, K. A., Walaas, S. I., Wang, J. K. and Greengard, P. 1986. Widespread occurrence of " $87 \mathrm{kDa}$," a major specific substrate for protein kinase C. Proc. Natl. Acad. Sci. U.S.A. 83: 2822-2826. [Medline] [CrossRef]

2. Baudry, M. and Bi, X. 2016. Calpain-1 and calpain-2: the yin and yang of synaptic plasticity and neurodegeneration. Trends Neurosci. 39: 235-245. [Medline] [CrossRef]

3. Biamonte, F., Latini, L., Giorgi, F. S., Zingariello, M., Marino, R., De Luca, R., D’llio, S., Majorani, C., Petrucci, F., Violante, N., Senofonte, O., Molinari, M. and Keller, F. 2014. Associations among exposure to methylmercury, reduced Reelin expression, and gender in the cerebellum of developing mice. Neurotoxicology 45: 67-80. [Medline] [CrossRef]

4. Calabrese, B. and Halpain, S. 2005. Essential role for the PKC target MARCKS in maintaining dendritic spine morphology. Neuron 48: 77-90. [Medline] [CrossRef]

5. Castoldi, A. F., Onishchenko, N., Johansson, C., Coccini, T., Roda, E., Vahter, M., Ceccatelli, S. and Manzo, L. 2008. Neurodevelopmental toxicity of methylmercury: Laboratory animal data and their contribution to human risk assessment. Regul. Toxicol. Pharmacol. 51: 215-229. [Medline] [CrossRef]

6. Choi, A. L., Weihe, P., Budtz-Jørgensen, E., Jørgensen, P. J., Salonen, J. T., Tuomainen, T. P., Murata, K., Nielsen, H. P., Petersen, M. S., Askham, J. and Grandjean, P. 2009. Methylmercury exposure and adverse cardiovascular effects in Faroese whaling men. Environ. Health Perspect. 117: 367-372. [Medline] [CrossRef]

7. Daré, E., Götz, M. E., Zhivotovsky, B., Manzo, L. and Ceccatelli, S. 2000. Antioxidants J811 and 17ß-estradiol protect cerebellar granule cells from methylmercury-induced apoptotic cell death. J. Neurosci. Res. 62: 557-565. [Medline] [CrossRef] 
(A)

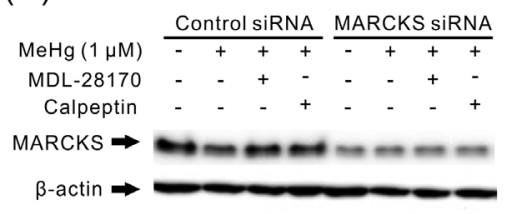

(B)

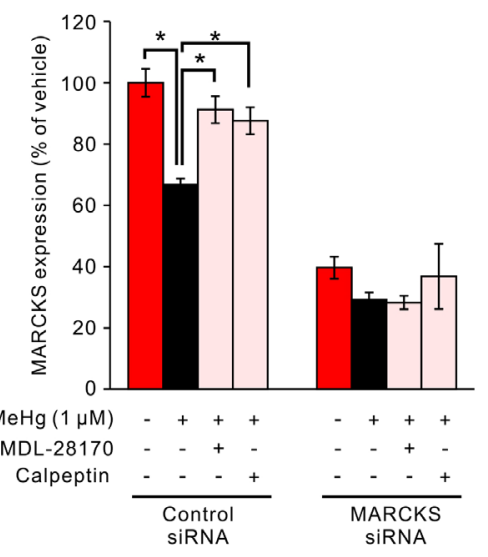

(C)

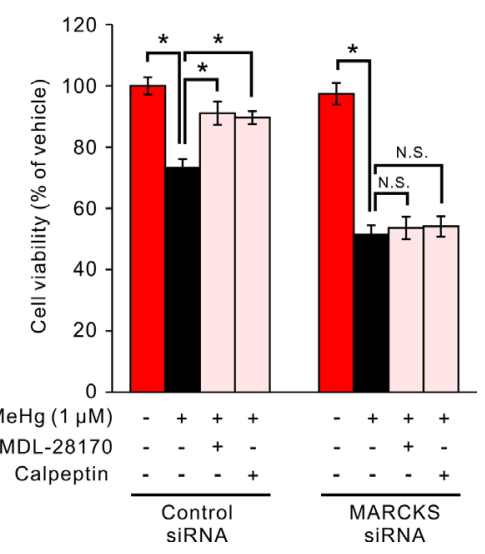

\section{SH-SY5Y cells}

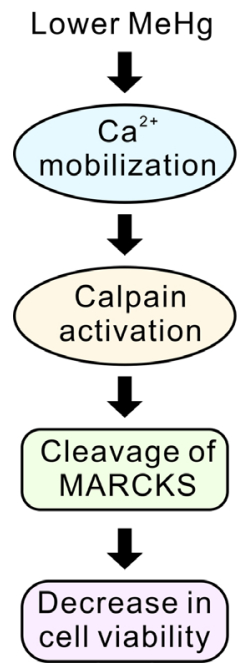

Higher MeHg

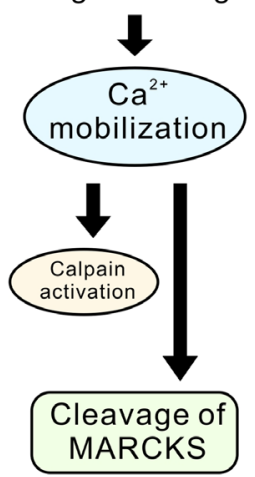

$\downarrow$

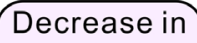

cell viability
EA.hy926 cells

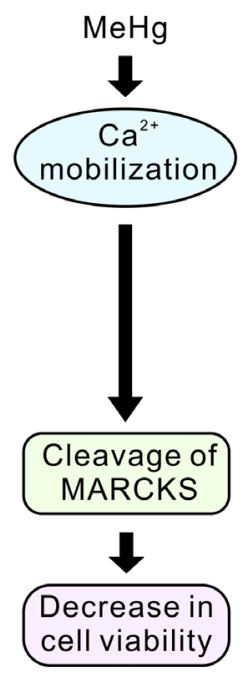

Fig. 6. Schematic representation of the regulation of full-length MARCKS amounts by MeHg in SH-SY5Y and EA.hy926 cells. The involvement of calpain in the regulation of MARCKS protein levels is dependent on cell types and the concentration of MeHg. In SH-SY5Y cells, MARCKS proteolysis by calpain mediates the cytotoxicity of the low concentration of $\mathrm{MeHg}$.

Fig. 5. Effects of calpain inhibitors on the MeHg-induced decrease in viability and on MARCKS content in SH-SY5Y cells with a MARCKS knockdown. Representative immunoblots of MARCKS and $\beta$-actin with specific antibodies are shown (A). Effects of $\mathrm{MeHg}$ and calpain inhibitors on full-length MARCKS amounts $(\mathrm{B}, \mathrm{n}=5)$ and viability $(\mathrm{C}, \mathrm{n}=8)$ in control and MARCKS knockdown cells. Data are expressed as a percentage of vehicletreated cells. Results are shown as mean \pm SEM. $* P<0.05$. N.S.: not significant.

8. Dedieu, S., Poussard, S., Mazères, G., Grise, F., Dargelos, E., Cottin, P. and Brustis, J. J. 2004. Myoblast migration is regulated by calpain through its involvement in cell attachment and cytoskeletal organization. Exp. Cell Res. 292: 187-200. [Medline] [CrossRef]

9. Dulong, S., Goudenege, S., Vuillier-Devillers, K., Manenti, S., Poussard, S. and Cottin, P. 2004. Myristoylated alanine-rich C kinase substrate (MARCKS) is involved in myoblast fusion through its regulation by protein kinase Calpha and calpain proteolytic cleavage. Biochem. J. 382: 1015-1023. [Medline] [CrossRef]

10. Eto, K. 1997. Pathology of Minamata disease. Toxicol. Pathol. 25: 614-623. [Medline] [CrossRef]

11. Eto, K., Tokunaga, H., Nagashima, K. and Takeuchi, T. 2002. An autopsy case of minamata disease (methylmercury poisoning)-pathological viewpoints of peripheral nerves. Toxicol. Pathol. 30: 714-722. [Medline] [CrossRef]

12. Fujitani, K., Kambayashi, J., Sakon, M., Ohmi, S. I., Kawashima, S., Yukawa, M., Yano, Y., Miyoshi, H., Ikeda, M., Shinoki, N. and Monden, M. 1997. Identification of mu-, m-calpains and calpastatin and capture of mu-calpain activation in endothelial cells. J. Cell. Biochem. 66: 197-209. [Medline] [CrossRef]

13. Gatlin, J. C., Estrada-Bernal, A., Sanford, S. D. and Pfenninger, K. H. 2006. Myristoylated, alanine-rich C-kinase substrate phosphorylation regulates growth cone adhesion and pathfinding. Mol. Biol. Cell 17: 5115-5130. [Medline] [CrossRef]

14. Graber, S., Maiti, S. and Halpain, S. 2004. Cathepsin B-like proteolysis and MARCKS degradation in sub-lethal NMDA-induced collapse of 
dendritic spines. Neuropharmacology 47: 706-713. [Medline] [CrossRef]

15. Islam, M. Z., Van Dao, C., Shiraishi, M. and Miyamoto, A. 2016. Methylmercury affects cerebrovascular reactivity to angiotensin II and acetylcholine via Rho-kinase and nitric oxide pathways in mice. Life Sci. 147: 30-38. [Medline] [CrossRef]

16. Jin, B. Y., Lin, A. J., Golan, D. E. and Michel, T. 2012. MARCKS protein mediates hydrogen peroxide regulation of endothelial permeability. Proc. Natl. Acad. Sci. U.S.A. 109: 14864-14869. [Medline] [CrossRef]

17. Johansson, C., Castoldi, A. F., Onishchenko, N., Manzo, L., Vahter, M. and Ceccatelli, S. 2007. Neurobehavioural and molecular changes induced by methylmercury exposure during development. Neurotox. Res. 11: 241-260. [Medline] [CrossRef]

18. Kalwa, H. and Michel, T. 2011. The MARCKS protein plays a critical role in phosphatidylinositol 4,5-bisphosphate metabolism and directed cell movement in vascular endothelial cells. J. Biol. Chem. 286: 2320-2330. [Medline] [CrossRef]

19. Lampe, W. R., Park, J., Fang, S., Crews, A. L. and Adler, K. B. 2012. Calpain and MARCKS protein regulation of airway mucin secretion. Pulm. Pharmacol. Ther. 25: 427-431. [Medline] [CrossRef]

20. Li, H., Chen, G., Zhou, B. and Duan, S. 2008. Actin filament assembly by myristoylated alanine-rich C kinase substrate-phosphatidylinositol-4,5diphosphate signaling is critical for dendrite branching. Mol. Biol. Cell 19: 4804-4813. [Medline] [CrossRef]

21. Liu, W., Xu, Z., Yang, T., Xu, B., Deng, Y. and Feng, S. 2017. Memantine, a low-affinity NMDA receptor antagonist, protects against methylmercury-induced cytotoxicity of rat primary cultured cortical neurons, involvement of $\mathrm{Ca}^{2+}$ dyshomeostasis antagonism, and indirect antioxidation effects. Mol. Neurobiol. 54: 5034-5050. [Medline] [CrossRef]

22. McNamara, R. K. and Lenox, R. H. 1997. Comparative distribution of myristoylated alanine-rich C kinase substrate (MARCKS) and F1/GAP-43 gene expression in the adult rat brain. J. Comp. Neurol. 379: 48-71. [Medline] [CrossRef]

23. McNamara, R. K., Hussain, R. J., Simon, E. J., Stumpo, D. J., Blackshear, P. J., Abel, T. and Lenox, R. H. 2005. Effect of myristoylated alanine-rich C kinase substrate (MARCKS) overexpression on hippocampus-dependent learning and hippocampal synaptic plasticity in MARCKS transgenic mice. Hippocampus 15: 675-683. [Medline] [CrossRef]

24. Meller, R., Thompson, S. J., Lusardi, T. A., Ordonez, A. N., Ashley, M. D., Jessick, V., Wang, W., Torrey, D. J., Henshall, D. C., Gafken, P. R., Saugstad, J. A., Xiong, Z. G. and Simon, R. P. 2008. Ubiquitin proteasome-mediated synaptic reorganization: a novel mechanism underlying rapid ischemic tolerance. J. Neurosci. 28: 50-59. [Medline] [CrossRef]

25. Monahan, T. S., Andersen, N. D., Martin, M. C., Malek, J. Y., Shrikhande, G. V., Pradhan, L., Ferran, C. and LoGerfo, F. W. 2009. MARCKS silencing differentially affects human vascular smooth muscle and endothelial cell phenotypes to inhibit neointimal hyperplasia in saphenous vein. FASEB J. 23: 557-564. [Medline] [CrossRef]

26. Nguyen, H. T., Nguyen, H. T., Islam, M. Z., Obi, T., Pothinuch, P., Zar, P. P., Hou, X., Van Nguyen, T., Nguyen, T. M., Van Dao, C., Shiraishi, M. and Miyamoto, A. 2016. Pharmacological characteristics of Artemisia vulgaris L. in isolated porcine basilar artery. J. Ethnopharmacol. $182: 16-26$. [Medline] [CrossRef]

27. Ohkubo, M., Miyamoto, A. and Shiraishi, M. 2016. Heavy metal chelator TPEN attenuates fura-2 fluorescence changes induced by cadmium, mercury and methylmercury. J. Vet. Med. Sci. 78: 761-767. [Medline] [CrossRef]

28. Pierozan, P., Biasibetti, H., Schmitz, F., Ávila, H., Fernandes, C. G., Pessoa-Pureur, R. and Wyse, A. T. 2016. Neurotoxicity of methylmercury in isolated astrocytes and neurons: the cytoskeleton as a main target. Mol. Neurobiol. 54: 5752-5767. [Medline] [CrossRef]

29. Poungsawai, J., Kanlaya, R., Pattanakitsakul, S. N. and Thongboonkerd, V. 2011. Subcellular localizations and time-course expression of dengue envelope and non-structural 1 proteins in human endothelial cells. Microb. Pathog. 51: 225-229. [Medline] [CrossRef]

30. Roman, H. A., Walsh, T. L., Coull, B. A., Dewailly, É., Guallar, E., Hattis, D., Mariën, K., Schwartz, J., Stern, A. H., Virtanen, J. K. and Rice, G. 2011. Evaluation of the cardiovascular effects of methylmercury exposures: current evidence supports development of a dose-response function for regulatory benefits analysis. Environ. Health Perspect. 119: 607-614. [Medline] [CrossRef]

31. Sakaue, M., Okazaki, M. and Hara, S. 2005. Very low levels of methylmercury induce cell death of cultured rat cerebellar neurons via calpain activation. Toxicology 213: 97-106. [Medline] [CrossRef]

32. Shao, H., Chou, J., Baty, C. J., Burke, N. A., Watkins, S. C., Stolz, D. B. and Wells, A. 2006. Spatial localization of m-calpain to the plasma membrane by phosphoinositide biphosphate binding during epidermal growth factor receptor-mediated activation. Mol. Cell. Biol. 26: $5481-5496$. [Medline] [CrossRef]

33. Shiraishi, M., Tanabe, A., Saito, N. and Sasaki, Y. 2006. Unphosphorylated MARCKS is involved in neurite initiation induced by insulin-like growth factor-I in SH-SY5Y cells. J. Cell. Physiol. 209: 1029-1038. [Medline] [CrossRef]

34. Shiraishi, M., Hangai, M., Yamamoto, M., Sasaki, M., Tanabe, A., Sasaki, Y. and Miyamoto, A. 2014. Alteration in MARCKS phosphorylation and expression by methylmercury in SH-SY5Y cells and rat brain. Environ. Toxicol. Pharmacol. 37: 1256-1263. [Medline] [CrossRef]

35. Stumpo, D. J., Graff, J. M., Albert, K. A., Greengard, P. and Blackshear, P. J. 1989. Molecular cloning, characterization, and expression of a cDNA encoding the "80- to $87-\mathrm{kDa}$ " myristoylated alanine-rich C kinase substrate: a major cellular substrate for protein kinase C. Proc. Natl. Acad. Sci. U.S.A. 86: 4012-4016. [Medline] [CrossRef]

36. Tapp, H., Al-Naggar, I. M., Yarmola, E. G., Harrison, A., Shaw, G., Edison, A. S. and Bubb, M. R. 2005. MARCKS is a natively unfolded protein with an inaccessible actin-binding site: evidence for long-range intramolecular interactions. J. Biol. Chem. 280: 9946-9956. [Medline] [CrossRef]

37. Tchounwou, P. B., Ayensu, W. K., Ninashvili, N. and Sutton, D. 2003. Environmental exposure to mercury and its toxicopathologic implications for public health. Environ. Toxicol. 18: 149-175. [Medline] [CrossRef]

38. Tofighi, R., Johansson, C., Goldoni, M., Ibrahim, W. N., Gogvadze, V., Mutti, A. and Ceccatelli, S. 2011. Hippocampal neurons exposed to the environmental contaminants methylmercury and polychlorinated biphenyls undergo cell death via parallel activation of calpains and lysosomal proteases. Neurotox. Res. 19: 183-194. [Medline] [CrossRef]

39. VAN Dao, C., Islam, M. Z., Sudo, K., Shiraishi, M. and Miyamoto, A. 2016. MARCKS is involved in methylmercury-induced decrease in cell viability and nitric oxide production in EA.hy926 cells. J. Vet. Med. Sci. 78: 1569-1576. [Medline] [CrossRef]

40. Wakabayashi, K., Kakita, A., Sakamoto, M., Su, M., Iwanaga, K. and Ikuta, F. 1995. Variability of brain lesions in rats administered methylmercury at various postnatal development phases. Brain Res. 705: 267-272. [Medline] [CrossRef]

41. Xu, B., Xu, Z., Deng, Y., Liu, W., Yang, H. and Wei, Y. G. 2013. MK-801 protects against intracellular Ca $\left({ }^{2+}\right)$ overloading and improves N-methylD-aspartate receptor expression in cerebral cortex of methylmercury-poisoned rats. J. Mol. Neurosci. 49: 162-171. [Medline] [CrossRef]

42. Yu, D., Makkar, G., Dong, T., Strickland, D. K., Sarkar, R. and Monahan, T. S. 2015. MARCKS signaling differentially regulates vascular smooth muscle and endothelial cell proliferation through a KIS-, p27 kip1- dependent mechanism. PLOS ONE 10: e141397. [Medline] [CrossRef]

43. Zadran, S., Jourdi, H., Rostamiani, K., Qin, Q., Bi, X. and Baudry, M. 2010. Brain-derived neurotrophic factor and epidermal growth factor activate neuronal m-calpain via mitogen-activated protein kinase-dependent phosphorylation. J. Neurosci. 30: 1086-1095. [Medline] [CrossRef]

44. Zhang, J., Miyamoto, K., Hashioka, S., Hao, H. P., Murao, K., Saido, T. C. and Nakanishi, H. 2003. Activation of mu-calpain in developing cortical neurons following methylmercury treatment. Brain Res. Dev. Brain Res. 142: 105-110. [Medline] [CrossRef] 